Article

\title{
Identifying the Risk Areas and Urban Growth by ArcGIS-Tools
}

\author{
Omar Hamdy ${ }^{1,2, *}$, Shichen Zhao ${ }^{1}$, Mohamed A. Salheen ${ }^{3}$ and Youhansen Y. Eid ${ }^{3}$ \\ 1 Department of Architecture and Urban Design, Graduate School of Human-Environment Studies, \\ Fukuoka 812-8581, Japan; zhao@arch.kyushu-u.ac.jp \\ 2 Department of Architectural Engineering, Faculty of Engineering, Aswan University, Aswan 81528, Egypt \\ 3 Department of Architectural Engineering, Faculty of Engineering, Ain Shams University, Cairo 11566, Egypt; \\ mohamed_salheen@eng.asu.edu.eg (M.A.S.); youhansen.eid@eng.asu.edu.eg (Y.Y.E.) \\ * Correspondence: omargem56@yahoo.com; Tel.: +81-802-750-7202
}

Academic Editors: Ruiliang Pu and Jesus Martinez-Frias

Received: 21 July 2016; Accepted: 10 October 2016; Published: 26 October 2016

\begin{abstract}
Abouelreesh is one of the most at risk areas in Aswan, Egypt, which suffers from storms, poor drainage, and flash flooding. These phenomena affect the urban areas and cause a lot of damage to buildings and infrastructure. Moreover, the potential for the further realization of dangerous situations increased when the urban areas of Abouelreesh extended towards the risk areas. In an effort to ameliorate the danger, two key issues for urban growth management were studied, namely: (i) estimations regarding the pace of urban sprawl, and (ii) the identification of urban areas located in regions that would be affected by flash floods. Analyzing these phenomena require a lot of data in order to obtain good results, but in our case, the official data or field data was limited so we tried to obtain it by accessing two kinds of free sources of satellite data. First, we used Arc GIS tools to analyze (digital elevation model (DEM)) files in order to study the watershed and better identify the risk area. Second, we studied historical imagery in Google Earth to determine the age of each urban block. The urban growth rate in the risk areas had risen to $63.31 \%$ in 2001. Urban growth in the case study area had been influenced by house sizes, because most people were looking to live in bigger houses. The aforementioned problem can be observed by considering the increasing average house sizes from 2001 until 2013, where, especially in risky areas, the average of house sizes had grown from $223 \mathrm{~m}^{2}$ in 2001 to $318 \mathrm{~m}^{2}$ in 2013 . The findings from this study would be useful to urban planners and government officials in helping them to make informed decisions on urban development to benefit the community, especially those living in areas at risk from flash flooding from heavy rain events.
\end{abstract}

Keywords: urban planning; risk area; DEM; urban sprawl; Aswan; GIS

\section{Introduction}

Urban growth usually leads to the change of land use and the form of land cover in many areas around the world, especially in developing countries [1]. Moreover, urban areas have a natural tendency to extend in multiple directions, sometimes with growth even heading towards places prone to natural disasters. Hence, decision-makers and planners should mitigate this problem through risk management and by providing different alternatives. Urban sprawl, a serious problem for many rapidly developing countries, refers to the uncontrolled growth of an urban area resulting from poorly or totally unplanned urbanization [2]. Considering that around half of the world's population lives in urban areas [3], and the encroachment of urban land uses on non-urban land has become a common phenomenon throughout developing countries [4], this is a notable issue that requires further study. 
Nowadays, water related disasters (floods, droughts, and tropical storms) are already a major challenge for sustainable human development [5-7]. Floods and/or flash floods are among the most catastrophic natural hazards in the world, causing the largest amount of deaths and property damage [8]. Recently, problems related to flooding have been greatly increased [9]. Prompt hazard zoning made at the meso-scale (i.e., city-level) can be used as decision-making tool for a fast and simplified screening of critical areas [10].

A flash flood can be defined as a flood that threatens damage at a critical location in the catchment, where the time for the development of the flood from the upstream catchment is less than the time needed to activate warning, flood defense, or mitigation measures downstream of the critical location [11]. Floods can influence many aspects of human life due to their destructive effects and create significant expenses on mitigation efforts. Heavy rains, land-use change in basin areas, and various engineering applications contribute to the magnitude and frequency of flood events [12]. Urban flash floods are flood events which cause damages in small catchment areas of less than $100 \mathrm{~km}^{2}$ (and even less than $10 \mathrm{~km}^{2}$ ) and are caused by small-scale rain events with volumes that far exceed the rainfall predictions and considerations originally factored into the design of local hydrological structures [13].

Flash floods, especially in urban areas, may contain hazardous materials, broken electric lines, sewage, etc. Explosions and fires during flash floods are not uncommon [14]. In urban areas, the impacts caused by floods can be very high because the areas affected are densely populated and contain vital infrastructure [15]. Expanding urban environments result in a greater risk of flash floods because urbanization generally results in increasing flood risk when compared to rural environments [14].

Human activities such as unplanned rapid settlement development, uncontrolled construction of buildings in general, and major land use changes can influence the spatial and temporal pattern of hazards [9]. The likelihood of a flood event (i.e., the flood hazard) is consequently increasing in those watersheds that are prone to or subject to anthropogenic disturbances [16]. The impact of urbanization on the natural watershed processes is resulting in a large increase in flash flood occurrences [14].

The houses of poor people in these most vulnerable informal settlement areas are typically constructed with materials and techniques that cannot resist extreme weather or natural disasters [17]. Rapid urbanization in low-income and middle-income nations tends to take place in such relatively high-risk areas, thereby placing an increasing proportion of the economies and populations of those countries at risk [18,19].

A watershed is defined as natural hydrologic entity that covers a specific area of land surface from which rainfall runoff flows to a defined drain, channel, stream, or river at any point [20]. A watershed is a natural or disturbed system that functions in a manner to collect, store, and discharge water from a common outlet, such as a larger stream and lakes [21]. A watershed represents an area of land where surface water from rain and melting snow, or ice, converges to a single point [19].

Watershed delineation can be done manually or automatically. However, using manual watershed delineation techniques for large basins is very time consuming and requires good quality topographic maps. After the development of reliable digital elevation models (DEMs), automatic watershed delineation has become very popular and has proven to be advantageous over manual methods when study areas are large and/or numerous [22]. Automated extraction methods are the most efficient approach when DEM cell size is significantly smaller than the watershed dimensions [12].

Identification of drainage networks within basins or sub-basins can be achieved using traditional methods such as field observations and topographic maps, or alternatively with advanced methods using remote sensing and DEMs [23-25].

One exciting ability afforded by Google Earth (GE) is the opportunity to look at changes in land cover over time. Historical Imagery is a new map display option in Google Earth 5.0 [26]. Moreover, a new capability of the GE plug-in (v6) is access to historical imagery with a time slider [27]. The United Nations' paired imagery is particularly useful for this exercise because it has been selected 
to represent a variety of causes of landscape change [28]. Google Earth now hosts high-resolution $(<2.5 \mathrm{~m})$ imagery from 2000 to 2010, with most images being from 2003 to 2007 [27,29].

Google Earth's high resolution imagery offers many important features for land-use/land-cover (LULC) mapping in that they: (i) are free for non-profit use; (ii) have sufficient spatial and color details to distinguish basic LULC classes; (iii) are geo-referenced with sufficient accuracy for LULC mapping; and (iv) range in date from 2000 to the present, allowing temporal sampling [27].

Manual photointerpretation has the advantage of identifying real world objects rather than the image objects extracted in object-based classification approaches [30]. Several recent studies have used visual interpretation of high resolution imagery in the GE desktop application to provide low-cost and reasonably accurate reference data, both for producing land-cover maps and testing their accuracy [27]. Despite advances in automated and semi-automated classification, manual photointerpretation still remains, to a good extent, the method of choice for producing fine-scale forest and land-cover maps that cannot be made in automated extraction [30]. It is strongly recommended to consult the Google Earth historical imagery to help determine the feasibility of studies on coastal landscape dynamics [31]. It may be the only suitable strategy for identifying such diverse and fine-scale urban land uses such as urban agriculture, particularly on the scale of the home garden [30].

\section{The Impact of Natural Disasters on Urban Growth}

The world has witnessed an alarming increase in the frequency and severity of disasters, with 240 million people, on average, being affected by natural disasters worldwide each year between 2000 and 2005. In 2007 alone, 414 natural disasters were reported, killing 16,847 persons, injuring or displacing more than 211 million others, and causing damage estimated at over US \$74.9 billion [32]. There has been more frequent extreme weather events associated with increasing climatic changes. Hydrological (essentially floods) and meteorological (storms) disasters are the major contributors to this pattern. In recent decades, the number of reported hydrological disasters has been increasing by $7.4 \%$ annually, on average. At the same time, there has also been an upward trend in population growth, with an average annual growth rate of $8.4 \%$ in the 2000 to 2007 period [32]. Flash floods are usually characterized by raging torrents after heavy rains that rip through river beds, urban streets, or mountain canyons, sweeping everything before them [33]. The phenomenon of the flash flood is one of the most difficult natural hazards to predict in terms of time and place of occurrence. As a result, it is challenging for the concerned authorities and communities to respond appropriately to flash flood events; effective response plans are indispensable tools to mitigate the danger of flash floods [34].

The watersheds that are located to the east of the River Nile, in the region between Edfu and Aswan cities, are dangerous, particularly in the area of Kom Ombo and to the east of Aswan. In May of 1979, a runoff spate resulted in the disruption of local rail lines, affecting the central areas of Edfu, Kom-Ombo, and Aswan, and leading to the collapse of 200 houses.

In addition to the disruption of rail lines and agricultural roads, some of which had become blocked by boulders that had been deposited by the force of the floodwater, the torrents of water from the flooding event also resulted in the death of three children who had become trapped under the rubble of collapsing buildings, and around 300 families had displaced. These floods repeated in October later that same year, which led to the collapse of more than 300 buildings and cracking in the structures of a large number of other buildings. Moreover, these aforementioned torrents have been accompanied by dust storms, thunderstorms, cyclonic rain, and frequent floods in the years 1980, 1987, 2005 , and $2010[35,36]$.

Severe hurricanes struck the province of Aswan on the evening of 17 January 2010. There were continuous torrential rains for about half an hour. More than 50 high voltage electrical pylons fell to the ground, causing power to the Aswan province be cut off. Subsequently, the rains which had accumulated on the eastern mountains turned into a torrent that took lives and swept away property, causing much destruction and havoc in its wake. Buildings that were not swept away suffered from cracks because of direct rainfall, and were in danger of collapsing. The rains and severe storms also 
caused damage to thousands of acres of crops, uprooting trees, as well as damaging tons of harvested dates which had been put out to dry under the sun.

The catastrophe happened at the village of "Abouelreesh", located at a distance of $5 \mathrm{~km}$ north of Aswan, adjacent to the Red Sea Mountains; the footprint of the village covers an area with a length of $500 \mathrm{~m}$ in the north-south orientation, with a depth of $1300 \mathrm{~m}$ in the east-west orientation. The most vulnerable places to torrents of floodwater were houses that had been built along the railway to the east, until the mid-point of the mountain. The competent administrative authorities had alerted the residents to the potential dangers of this region and its accompanying implications for construction in the area because of the stormwater risks (Figure 1).
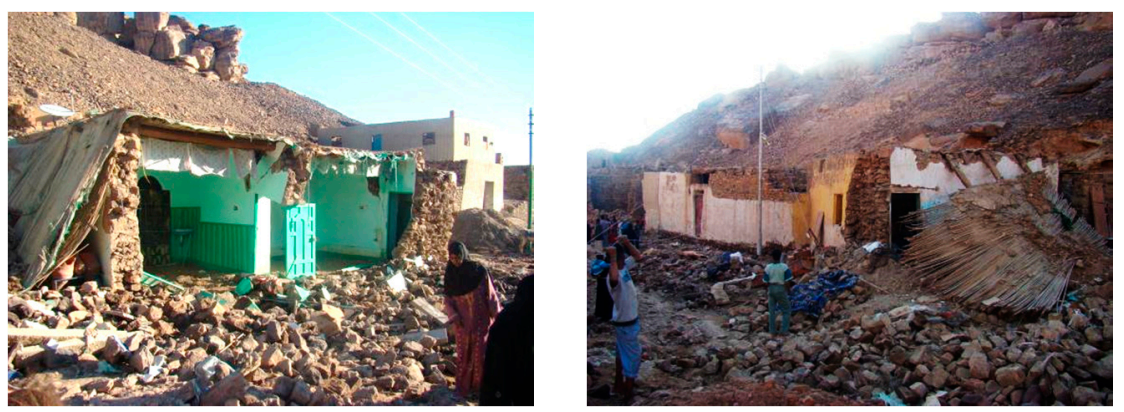

Figure 1. Buildings are destroyed in Abouelreesh village after a torrent of floodwater in 2010.

Despite previous warnings, due to the lack of other available settlement areas, people were nonetheless forced to build and settle in this region. At the time of the flood in 2010 the damage was not substantial because the population of people living in the area was relatively small [37], with only approximately 20,000 inhabitants in the region. The torrents of floodwater caused the demolition of about 25 houses and partially damaged another 50 or so houses, which were mostly built out of stone and clay mortar.

Further away from the city of Aswan-about $15 \mathrm{~km}$ to the north and $4 \mathrm{~km}$ eastward in area inhabited by tribes of Ababdh that number upwards of about 3000 people-there was additional damage, with the complete destruction of 10 houses and partial damages to about 30 homes, in addition to damages to large tracts of agricultural land and the uprooting of many trees (See Figure 2 for accompanying images) [36].
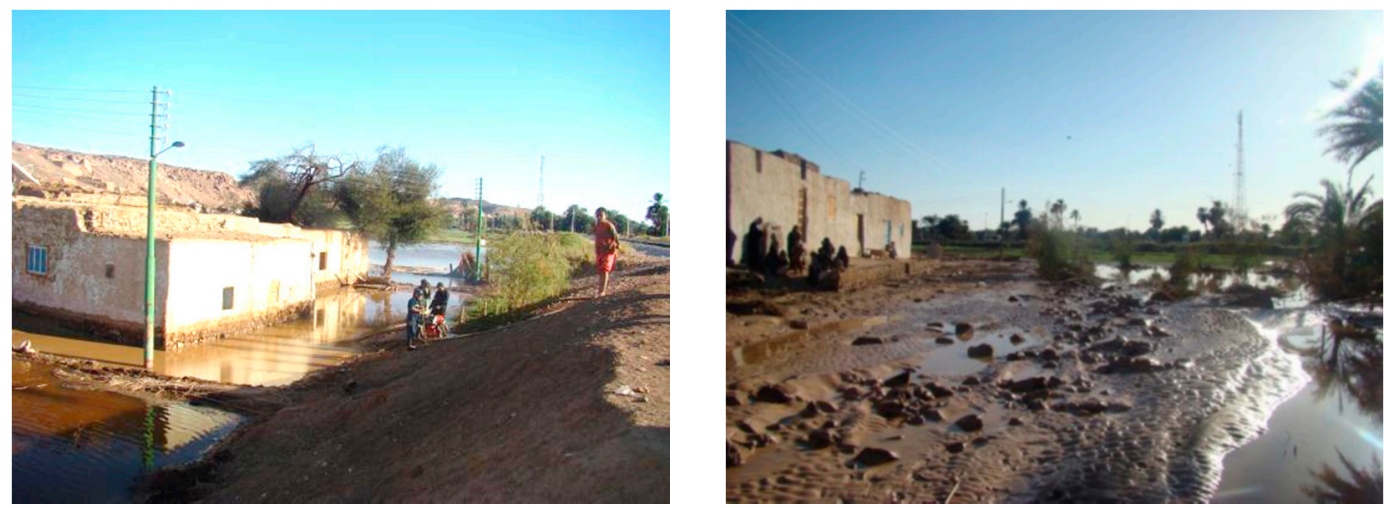

Figure 2. Roads and buildings affected by floodwater torrents in Egypt.

The aim of this paper is to address key issues for urban growth management, namely by: (i) providing an estimation of the pace of urban sprawl in the area surrounding Aswan city by using manual photointerpretation for Google Earth high resolution imagery; (ii) identifying urban areas located in regions that will be affected by flashfloods in the case study area; and (iii) examining 
the characteristics of urban growth in risk areas. This paper uses the free Google Earth data source to achieve the above mentioned aims. The findings would be useful to urban planners and decision makers from developing countries where there is generally a dearth of official and high resolution data.

\section{Study Area}

The study area (Northern Abouelreesh village) is located in the province of Aswan, in southern Egypt. It lies between longitudes $32^{\circ} 52^{\prime} \mathrm{E}$ to $32^{\circ} 55^{\prime} \mathrm{E}$ and latitudes $24^{\circ} 10^{\prime} \mathrm{N}$ to $24^{\circ} 14^{\prime} \mathrm{N}$. The study area is bordered to the east by mountains and from the west by an agricultural region, and the River Nile. Figure 3 shows the location of the case study area in relation to Egypt and the rest of the world.

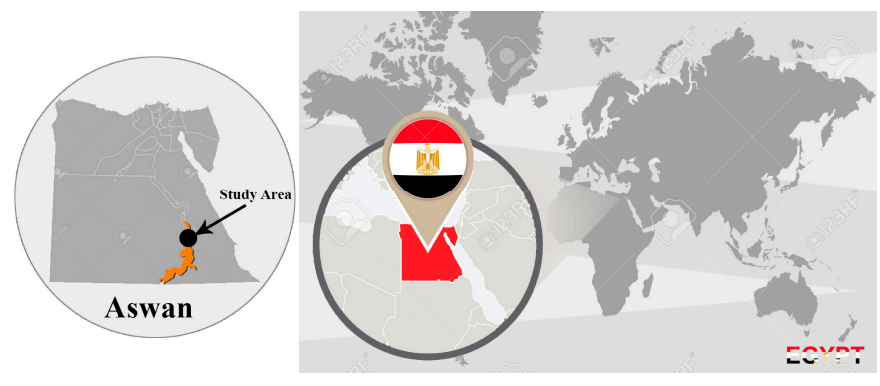

Figure 3. The study area in relation to Egypt and the world.

The area of urban development approved for northern Abouelreesh in 2010 was approximately 183.33 ha. While roads, pathways, and urban spaces occupied 42.94 ha, the entire allocated area was not suitable for urbanization. The designated area also encompassed within its boundaries land set aside for private property (about $27.25 \mathrm{ha}$ ), desert land (approximately $51.09 \mathrm{ha}$ ), and farmland (about 1.91 ha). The population of the village was about 9896 in 1986, rising to 12,206 inhabitants in 1996, then to 13,189 in 2006.

The growth rate in this area was $2.12 \%$ per annum in the period of 1986-1996, decreasing to $0.78 \%$ per annum from 1996 to 2006 . The average population growth rate was $1.45 \%$ per annum from 1986 to 2006. The total population of the village in 2010 was about 14,202 and the average family size was about 4.16 [37]. The villagers in this region lived in constant fear of natural disasters due to the proximity of the nearby watersheds, located to the east of the River Nile in the region between the cities of Edfu and Aswan. A particular case for concern existed in the vicinity of Kom Ombo and areas east of Aswan.

\section{Methodology}

Geographic Information Systems (GISs) are widely used to support water quantity and quality studies. GIS and digital elevation models (DEMs) can be used to perform watershed delineation to a point, a range, or an area of interest, which is usually one of the first steps in such studies. This paper presents the methodology that preprocesses the DEM in order to facilitate interactive watershed delineation. As a result, watersheds can be delineated quickly and with consistent response times; moreover this process takes advantage of using free and easily accessible data, such as DEM files [38].

The research methodology employed tried to determine the active watersheds which have previous histories and/or the present probabilities of being areas at risk from flash flooding events and attempted to analyze the direction of urban growth in these areas based on the available satellite data. The study was conducted in several steps. First, we identified risky areas (which included the stormwater drains network and the boundary zone (watersheds)) using the Digital Elevation Model (DEM) and made different analyses with the hydrology toolbox in Arc GIS in order to get the storm drains and watershed that were likely to be affected by potential torrents of floodwater (Figure $4 a, b$ ). 


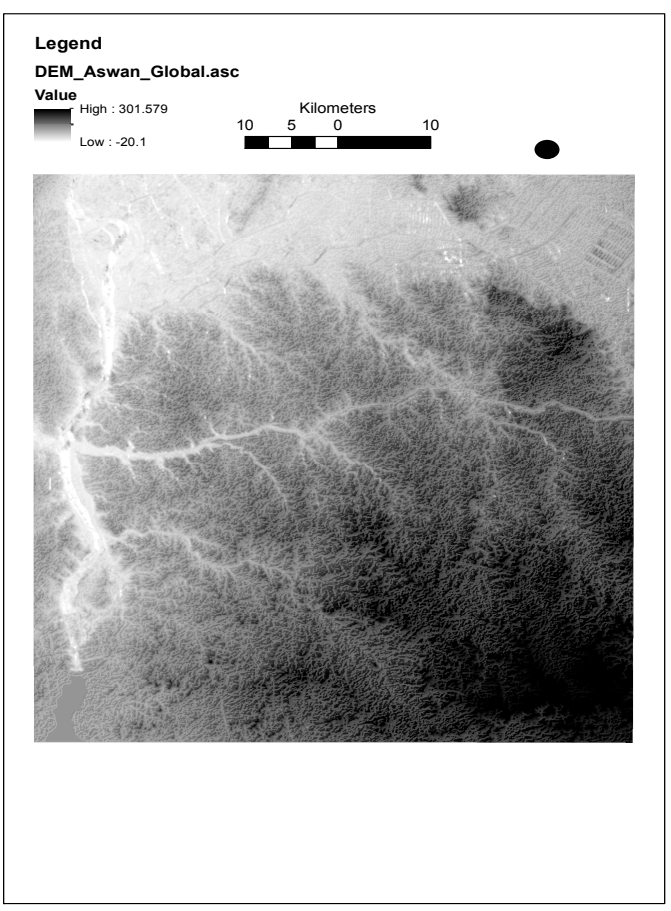

(a)

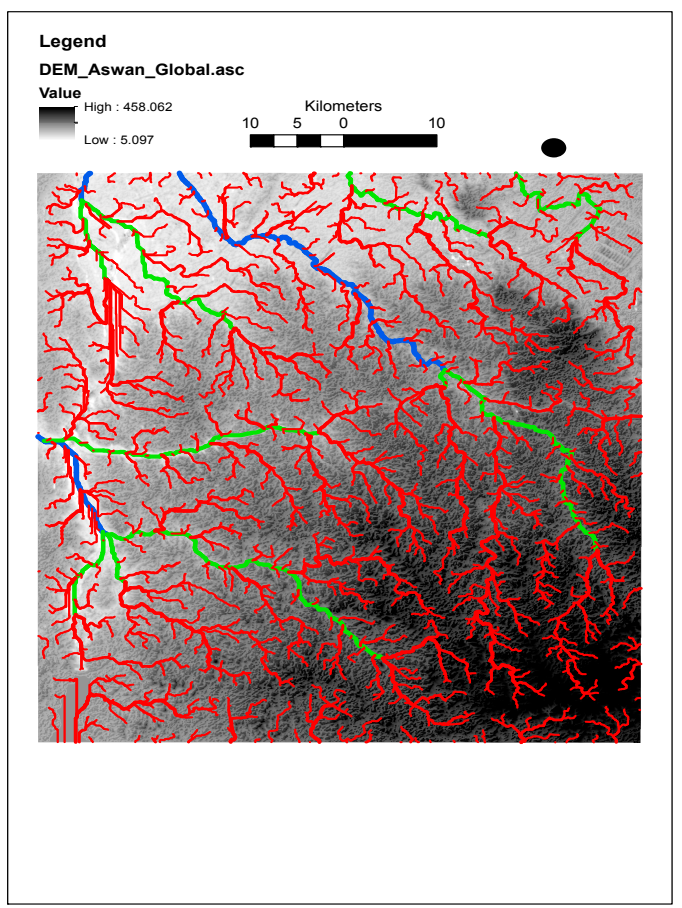

(b)

Figure 4. Digital elevation model (DEM) file and water streams. (a) Study area DEM file; (b) Study area water streams network.

Second, the research methodology in this section was aimed at studying the case study region in different periods of time in order to identify growth trends. The official detailed plan for the study area and information updates of building construction projects in subsequent years were examined by using Google Earth to manually extract the relevant data. This was followed by a visual analysis of high-resolution aerial images of the city in Google Earth. Manual photointerpretation of high-resolution images in Google Earth was the key process in this mapping methodology. The method described in this paper requires only personnel trained in photointerpretation, which necessitates only minimal training (at most) in GIS, Internet access, and a computer with a relatively high-resolution monitor.

Finally, using Arc GIS software to analyze the urban areas results, we studied the land use and the average area of the building for each period and determined the ratio of the urban growth rate from one period to another. In addition, the study area was divided into two region types according to their exposure to the flooding risk: first, risky areas and second, safe areas, which were deemed to be far from the reach of potential floodwaters.

\section{Data Analysis}

Using Google Earth, we studied and analyzed both the buildings' ages and the land use in the study area. Figure 5 shows the distribution of land uses inside the village which is divided into a small section in the north and big section in the south with the two sections separated by agricultural land. The greater part area from the east has mountainous and rugged terrain, there is agricultural land and the Nile River in the west, and in the south the village of southern Abouelreesh is located, as shown in Figure 6. 


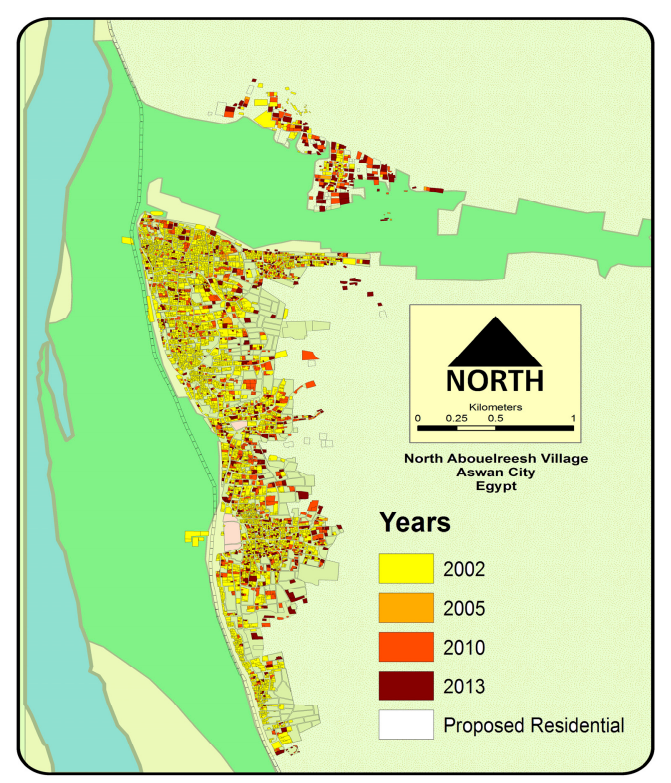

Figure 5. A map showing the current status of the village of Abouelreesh (with the years in which construction occurred designated according to color).

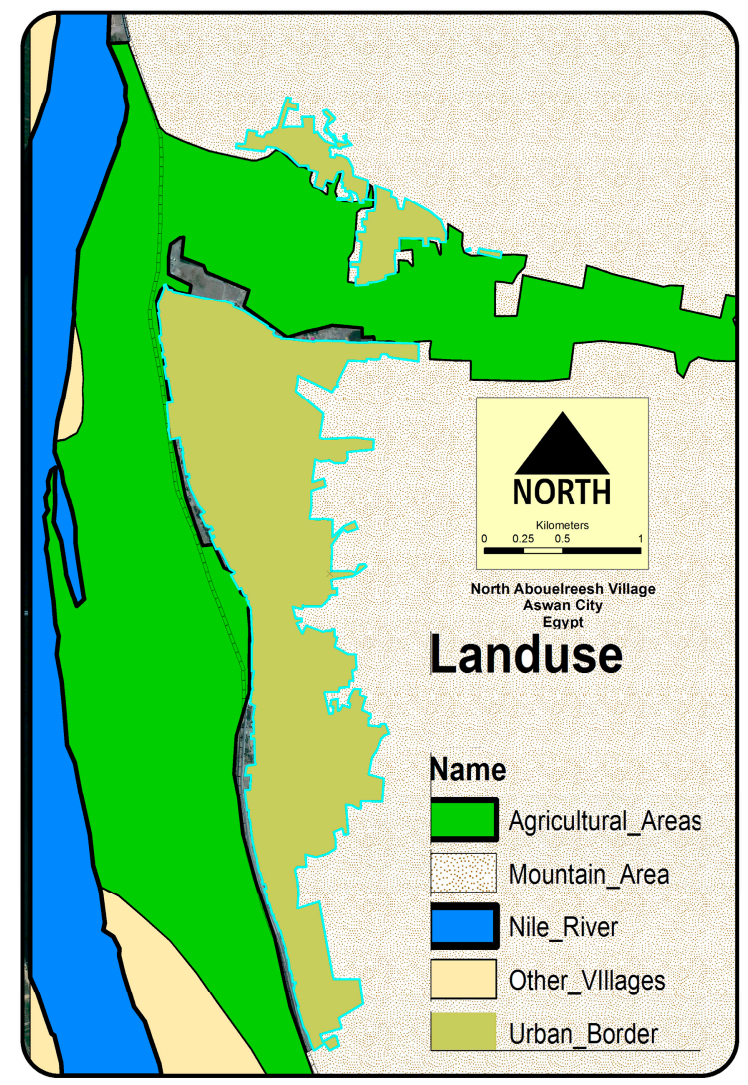

Figure 6. A map showing the current status of the land use in and around the village of Abouelreesh.

\section{Watershed Delineation}

Digital elevation models (DEMs) are an important source of information in GIS applications. They have been widely used for modeling surface hydrology, including the automatic delineation of catchment areas, erosion modeling, or automatic drainage network extraction [39]. Delineation of drainage networks for catchments is very important for partitioning sub-basins and for the application 
of a distributed hydrologic model. Many available algorithms automatically extract river network segments and associated sub-basins from a digital elevation model (DEM). DEM is a type of spatial data set that reflects the topography of a river basin [40].

Similar to the hydrologic tool in ArcGIS, the Preprocessing Program has various useful functions such as determination of flow direction, flow accumulation calculation, drainage extraction, and so on [40]. With the development of computer and information technology, distributed hydrologic models have increasingly become an important research focus, in which watershed delineation based on DEM (Digital Elevation Model) is a key step and priority [1]. Successful and accurate watershed delineation is the precondition for acquiring credible results in the running of runoff, sediment, and water quality models [41].

Watersheds can be delineated in Geographical Information Systems (GISs) by keeping track of flow direction and the number of upstream points for each grid point in a DEM. Once the watershed is delineated it can then be used to crop out data from other layers (e.g., land cover, area, etc.) that are useful in hydrology [42]. We will use the Spatial Analyst extension in ArcGIS in following steps (Table 1).

Table 1. The steps used to get watershed and water stream related information from DEM files.

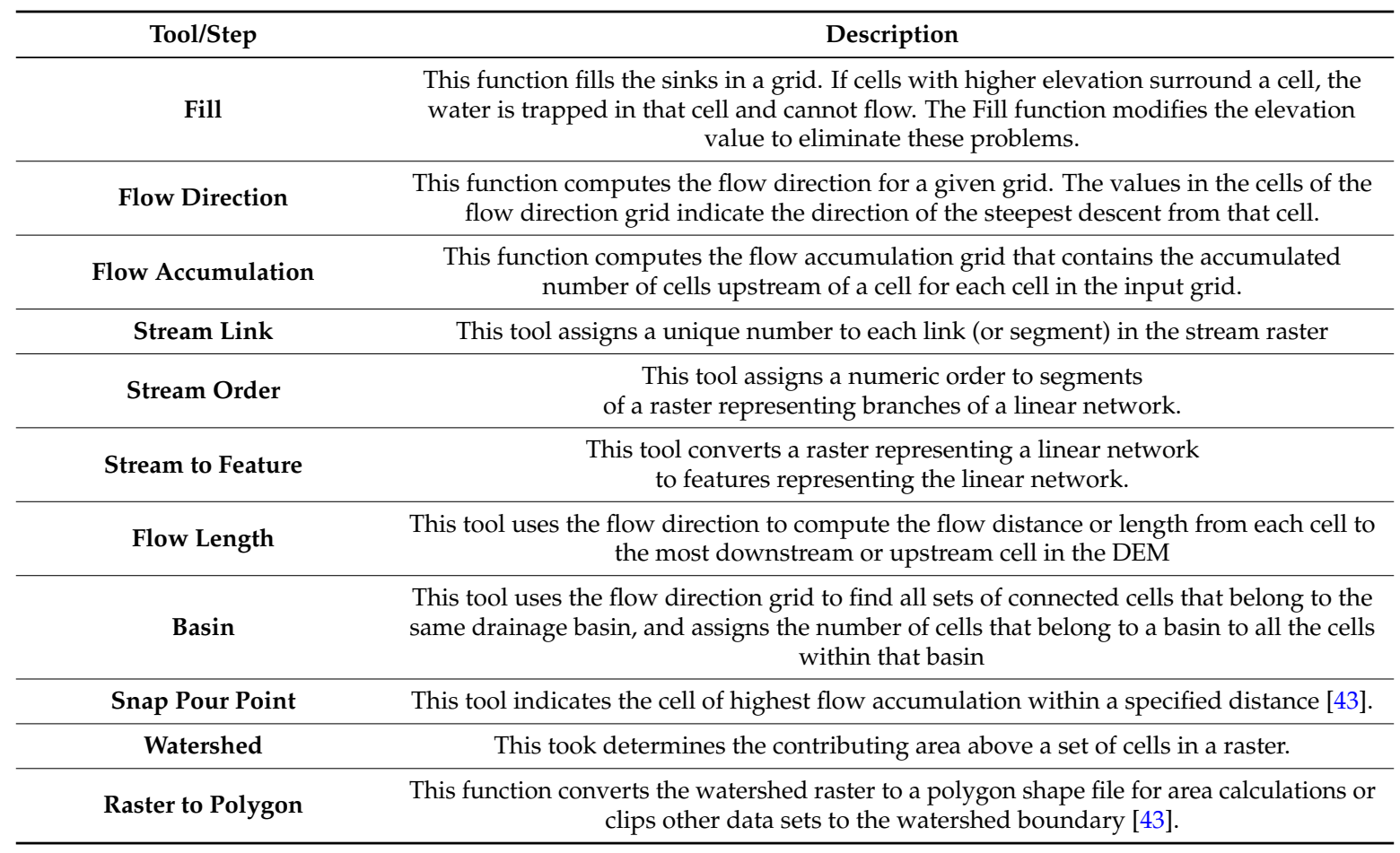

After we made the analyses with the hydrology toolbox, we obtained the watershed boundaries and water streams network that affect the case study area. The watershed boundaries represent a high the risk area during heavy rain events; if an urban area is included within watershed boundaries then it will be at risk from flash flooding.

\section{Results and Discussion}

\subsection{Urban Growth toward Risk}

We made an overlay between watershed (risky area) layers and urban area layers using the Arc GIS software to divide the urban area into two groups (Figure 7). The first group was located in a safe area which was about 77.26 ha; this area was deemed to be safe from potential flash flooding events since the expected water depth was zero on account of the area being located out of identified 
watersheds areas. The second group was the risky area, which was located within areas identified as being within watershed boundaries where the risk from flash food events represents a high probability (the risk was about 53.64\% in 2001, it increased to $71.35 \%$ and $74.69 \%$ in 2005 and 2009, respectively, and it reached $82.13 \%$ in 2013). A very high percentage of urban areas were observed to be located in risky areas. It was found that most people were living in dangerous areas (Table 2).

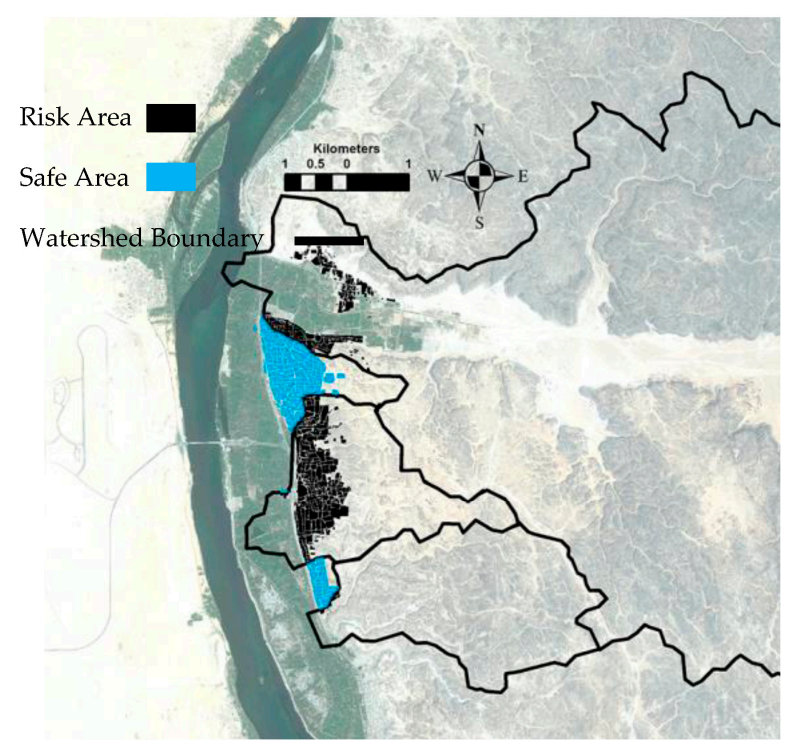

Figure 7. Map showing the at risk areas, the safe areas, and the watershed boundaries for the study area.

Table 2. Urban distribution in areas deemed to be either safe or at risk from potential floodwaters.

\begin{tabular}{|c|c|c|c|c|c|c|c|c|c|c|}
\hline \multirow{2}{*}{ Area } & \multicolumn{2}{|c|}{2001} & \multicolumn{2}{|c|}{2005} & \multicolumn{2}{|c|}{2009} & \multicolumn{2}{|c|}{2013} & \multicolumn{2}{|c|}{ Total years } \\
\hline & ha & $\%$ & ha & $\%$ & ha & $\%$ & ha & $\%$ & ha & $\%$ \\
\hline Risk Areas & 63.31 & 53.64 & 3.29 & 53.64 & 24.56 & 53.64 & 23.94 & 53.64 & 115.10 & 62.33 \\
\hline Safe Areas & 54.71 & 46.36 & 1.32 & 46.36 & 8.32 & 46.36 & 5.21 & 46.36 & 69.56 & 37.67 \\
\hline Total & 118.02 & 100.00 & 4.61 & 100.00 & 32.88 & 100.00 & 29.15 & 100.00 & 184.66 & 100.00 \\
\hline Years Percentages & \multicolumn{2}{|c|}{$63.91 \%$} & \multicolumn{2}{|c|}{$2.50 \%$} & \multicolumn{2}{|c|}{$17.80 \%$} & \multicolumn{2}{|c|}{$15.79 \%$} & \multicolumn{2}{|c|}{$100.00 \%$} \\
\hline
\end{tabular}

The land use distribution over a period of 12 years was compared. As indicated in Table 2, development of urban areas from 2001 to 2013 in the at risk areas was 115.10 ha (62.33\%), compared with 69.56 ha $(37.67 \%)$ in the safe areas. In $2001,54.71$ ha $(46.36 \%)$ of the total urban areas were in safe areas. The year 2005 saw the smallest urban expansion in the period under study, with 4.61 ha; the safe areas and at risk areas represented $46.36 \%$ and $53.64 \%$ of the urban land use, respectively. The authors of Figures 7 and 8 indicate that, generally, during the period of study, urban expansion in the at-risk areas was greater than that in the safe areas.

The most urban growth (24.56 ha) occurred in 2009 , and this growth was located in the at-risk areas (Figure 8). Figure 9 shows that $78.65 \%$ of the urban growth located in the safe areas had been built before 2001. This was slightly higher than the proportion of growth in the at risk areas $(55.01 \%)$ completed prior to the same point in time. In addition, Figure 10 shows the annual rate of urban growth rising from a low rate of $5.19 \%$ in 2005 for the at risk areas to $36.88 \%$ in 2009 , before declining slightly to $26.26 \%$ in 2013 . The trend in urban growth in the safe areas followed closely, reaching $14.85 \%$ in 2009 , and $8.1 \%$ in 2013. 
SUM TOTAL AREA ( HA )

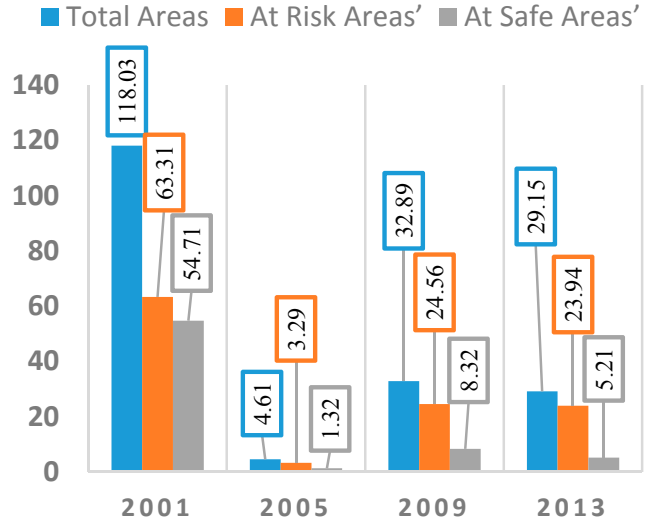

Figure 8. Urban areas from 2001 to 2013.

ANNUAL EXTEND_\%

- Total Areas at Risk Areas' = At Safe Areas'

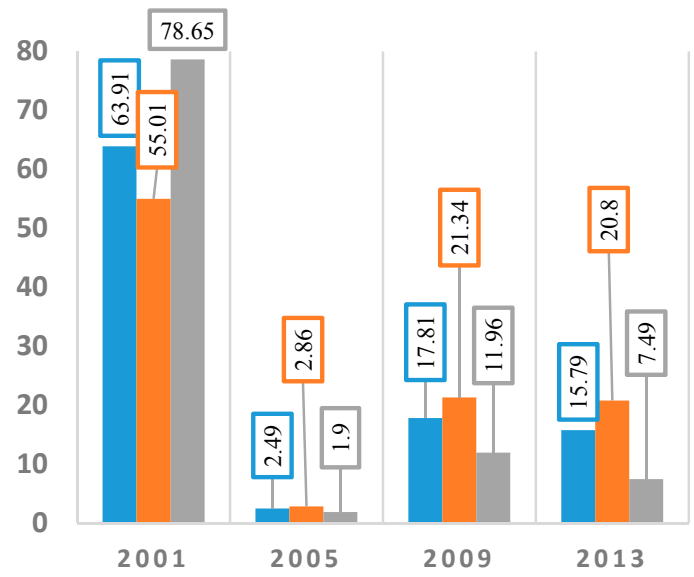

Figure 9. Proportion of safe and at risk areas developed according to year.

INCREASE_\%

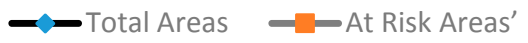

$\triangle$ At Safe Areas'

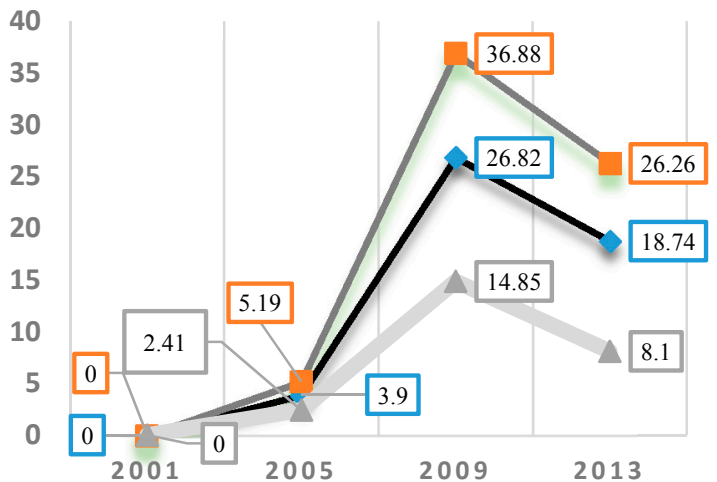

Figure 10. Annual rate of increase in developed safe and at risk areas. 


\subsection{Risk Areas Distributions}

Urban areas that were designated to be at risk were distributed according to three categories based on the location of the watersheds, as shown in Table 3. In the at risk areas, the urban area allocated in the second watershed was the biggest category, occupying 72.62 ha or about $63.07 \%$ of the total at risk area. The second value was the urban area which was located in the first watershed; it occupied 41.97 ha or about $36.49 \%$ of the total at risk area. Lastly, urban areas in the third watershed represented the smallest category with 0.51 ha or about $0.44 \%$ of the at risk area. These statistics indicate that the urban area in the second watershed formed the largest category of at risk urban area (115.10 ha). Unfortunately, the biggest proportion of urban areas (62.33\%) were in the at risk area.

Table 3. The watershed at risk area statistics.

\begin{tabular}{ccc}
\hline Categories & Urban Area (ha) & Percentage $\%$ \\
\hline Watershed (1) & 41.97 & $36.49 \%$ \\
Watershed (2) & 72.62 & $63.07 \%$ \\
Watershed (3) & 0.51 & $0.44 \%$ \\
Total Risk Area & 115.10 & $62.33 \%$ \\
Total Safe Area & 69.56 & $37.67 \%$ \\
Total Urban Area & 184.66 & - \\
\hline
\end{tabular}

\subsection{Relationship between Urban Growth and Size of Residence Blocks}

We used Arc GIS software to obtaining the total area of buildings for each period. We also calculated the average area of buildings for each year in order to make comparisons between them and find the urban growth rate. Next, we made a similar analyses with the study of safe areas and at risk areas in order to separately determine the total area and the average area of the buildings for each year in each region (as shown in Table 4).

Table 4. The average urban area divided into at risk areas and safe areas.

\begin{tabular}{ccccccc}
\hline Urban Area & Area & $\mathbf{2 0 0 1}$ & $\mathbf{2 0 0 5}$ & $\mathbf{2 0 0 9}$ & $\mathbf{2 0 1 3}$ & Total Ave \\
\hline & Total Areas & 241 & 257 & 314 & 346 & 267 \\
Average Total Area $\left(\mathbf{m}^{\mathbf{2}}\right)$ & At Risk Areas & 239 & 243 & 331 & 365 & 292 \\
& Safe Areas & 235 & 272 & 257 & 272 & 234 \\
\hline
\end{tabular}

It was observed that there was a change in the average size of buildings, from $241 \mathrm{~m}^{2}$ in 2001 to $346 \mathrm{~m}^{2}$, an increase of more than $100 \mathrm{~m}^{2}$ in just 12 years. From 2001-2005, the size of residence blocks in the safe area increased slightly from 235 to $272 \mathrm{~m}^{2}$. There was a small increase again from 257 to $272 \mathrm{~m}^{2}$ during the period of 2009-2013, but overall, the average size of buildings in the safe area increased from 235 to $272 \mathrm{~m}^{2}$ during the 2001-2013 period.

In contrast, the average house size in the at risk areas increased much more, from 239 to $365 \mathrm{~m}^{2}$ in the same period, thereby increasing by more than $50 \%$ from the previous area, while the a substantial increase from 257 to $314 \mathrm{~m}^{2}$ occurred in the second four years of the study period, (i.e., from 2005 to 2009). Table 4 shows that as the urban sprawl grew, so did the size of residence blocks. In the same context, it was observed that, on average, residence blocks in the at risk areas were bigger than those in the safe areas. The greatest discrepancy in size between residence blocks in the safe areas and those in the at risk areas was seen in 2013 , with the latter reaching more than $130 \%$ in average area as compared with the former.

After having analyzed the historical trends surrounding the size and designation of different spaces and areas, we noted that, overall, the average area of buildings increased from $241 \mathrm{~m}^{2}$ in 2001 to $346 \mathrm{~m}^{2}$ in 2013, thereby representing a 43\% increase in the average area occupied by individual buildings. Furthermore, when separately considering safe areas and at risk areas, we found that in safe areas the average area occupied by individual buildings increased from $235 \mathrm{~m}^{2}$ in 2001 to $272 \mathrm{~m}^{2}$ 
in 2013, thereby representing a 15\% increase. However, the biggest increase occurred in at risk areas, where the average area occupied by individual buildings was $239 \mathrm{~m}^{2}$ in 2001 and later reached to $365 \mathrm{~m}^{2}$ in 2013, thereby representing a 53\% increase. This serves as an indication that the population in the urban areas may have sprawled into at risk areas in search of more space (See Table 4 and Figure 11).

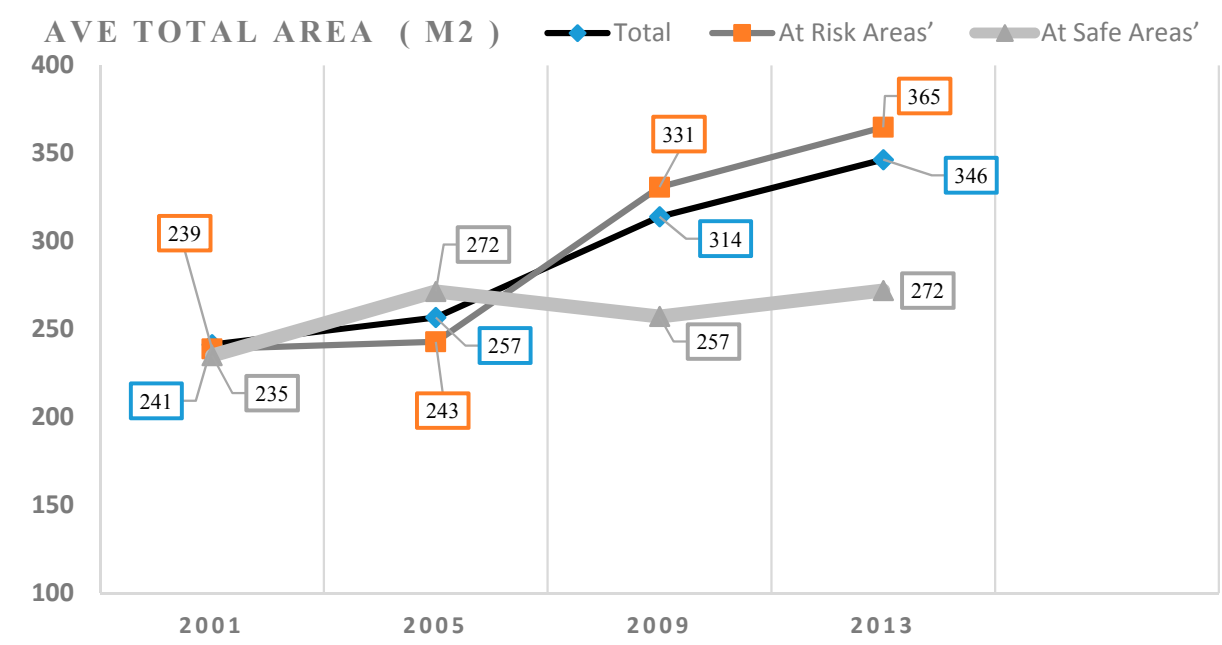

Figure 11. This graph shows the average area occupied by building units in safe areas, at-risk areas, and the overall urban area.

\subsection{Proposed Urban Area}

Studying the official detailed Plan for the study area was very important in order to understand the position of the government on urban growth in areas that have been designated as being at risk to potential floodwaters (Figure 12). The official Master Plan suggested the proposed urban area for housing and services which was to be valid up until 2020; we used the proposed shape file data to conduct analyses in Arc GIS in order to divide the proposed urban area based on the locations related to at-risk areas and safe areas.

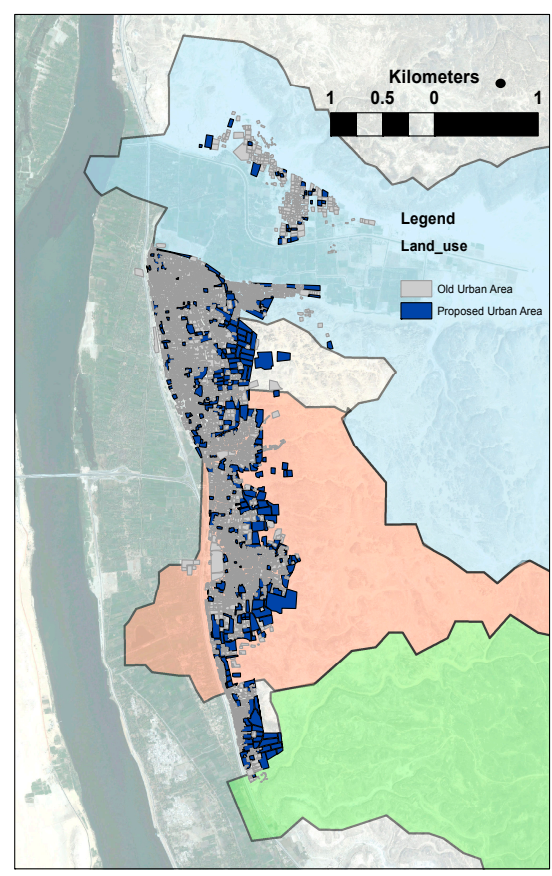

Figure 12. Distribution pre-existing and proposed urban area. 
The proposed urban area covered 97.40 ha across the entire village, but after we divided it according to risk designation, about 59.63 ha have been proposed for development in the at risk area (thus amounting to $61.22 \%$ of the total proposed area), and the proposed urban area located within designated safe areas was 37.78 ha (thus amounting to $38.78 \%$ of the total proposed area) (Table 5). This observation is particularly concerning because while originally the urban growth towards the at risk areas was indiscriminately determined by the local people, in this case, the proposed urban growth that has been directed by the government has approximately the same percentage of distribution of at risk land as the presently existing urban area.

Table 5. Proposed urban area as divided into at risk areas and safe areas.

\begin{tabular}{cccccc}
\hline Urban Area & Total Areas & \multicolumn{2}{c}{ At Risk Areas } & \multicolumn{2}{c}{ Safe Areas } \\
\hline Proposed urban area (ha) & 97.40 & 59.63 & 61.22 & 37.78 & 38.78 \\
Total pre-existing area & 184.66 & 115.10 & 62.33 & 69.56 & 37.67 \\
\hline
\end{tabular}

\section{Conclusions}

Villages in the Aswan Governorate are occasionally threatened by the risk of floodwater torrents which cause loss of lives and property, as well as damage to buildings and disruption to services. This study found that despite the risk of torrents, people still continued to build houses-in fact, even bigger ones-in the at risk area. Urban growth from 2001 and 2013 reflected this phenomenon.

After studying urban growth in Abouelreesh village in each of the following years 2001, 2005, 2009, and 2013, we considered the entire urban area in order to determine the ratio area that was designated as either safe or at risk areas. Our research indicated that Abouelreesh village is experiencing urban growth in at risk areas, with the $63.31 \%$ of urban areas designated as being within at risk areas in 2001. Given the inherent threats that this presents to the future of the village, the government needs to develop a plan to manage the risk in the village with the provision of alternatives for the population in order to help them avoid construction in at risk areas.

The use of free data in identifying the urban sprawl and watershed boundaries can generate primary results close to real life situations. This method would be helpful to decision makers and planners in countries which do not have enough data or do not have sufficient funding to bid for development projects, especially if it is necessary for studying the potential site(s) in order to avert the threat of natural disasters. This research used this free and easily accessible data (DEM files) to delineate the watersheds in the study area, which has previously been subjected to many flash flood events.

Urban growth in the at risk areas of this case study area, Abouelreesh, had special characteristics that were noteworthy. Firstly, the average size of residence blocks in the at risk area were considerably bigger than the residence blocks in the safe area, and also much bigger than those built in earlier years. The second characteristic concerned the government's unexplained distribution of proposed residential area, because more than $53 \%$ of the area would be located in the at risk areas.

Building location is one of many very important factors that attract people to certain areas and affect decision making for urban growth areas. In this study area, the average block size in risk area increased more than the average block size in safe areas; because the contour slope in safe area was sharper than the slope in risk area.

Urban growth in at risk areas is not only associated with the seeming interest of people in this village to get bigger houses, but it is also related to governmental decisions, whereby the government encouraged people to build in at risk areas by the provision of services and, moreover, proposed urban areas within at risk areas.

The current growth of some towns and villages in the regions within and surrounding Aswan places them at risk to water related natural disasters. The growth of these urban areas in the face risks to future floodwater events necessitates further study on the behavior of urbanization and urban growth. Moreover, future studies should consider the relationship between urban areas and risks and 
strive to find solutions for risk management and the protection of urban structure; we should study the causes of urban sprawl into at risk areas in order to try to better allow ourselves to avoid it.

Abouelreesh village is facing a notable problem in that significant growth of the village is occurring in areas at risk of potential floodwater torrents; as such, we must conduct further studies in order to identify solutions that will help redirect the urbanization toward safe areas and provide the means to manage the risk of future stormwater related damage in the village.

Future research on the urban sprawl in this region would allow for a better appreciation of how new urban areas would be exposed to the risk of torrents and floods. Hopefully, new findings would help to mitigate the loss of life and property.

Acknowledgments: This work would not have been possible without the financial support of the Egyptian Government and Cultural Affairs \& Missions Sector's funding of this research. As such, we give them all our deepest thanks for their support.

Author Contributions: Omar Hamdy conducted the analyses and wrote the manuscript. Omar Hamdy, Shichen Zhao, Mohamed A. Salheen, and Youhansen Y. Eid revised the paper.

Conflicts of Interest: The authors declare no conflict of interest.

\section{References}

1. Belal, A.A. Detecting urban growth using remote sensing and GIS techniques in Al Gharbiya governorate, Egypt. Egypt. J. Remote Sens. Space Sci. 2011, 14, 73-79. [CrossRef]

2. Noor, N.M. Determination of Spatial Factors in Measuring Urban Sprawl in Kuantan Using Remote Sensing and GIS. In Proceedings of the ASEAN Conference on Environment-Behaviour Studies, Hanoi, Vietnam, 18-21 March 2013.

3. Jalayer, F.; de Risi, R.; de Paola, F.; Giugni, M.; Manfredi, G.; Gasparini, P.; Topa, M.E.; Yonas, N.; Yeshitela, K.; Nebebe, A.; et al. Probabilistic GIS-based method for delineation of urban flooding risk hotspots. Nat. Hazards 2014, 73, 975-1001. [CrossRef]

4. Yue, W.Z.; Liu, Y.; Fan, P.L. Measuring urban sprawl and its drivers in large Chinese cities: The case of Hangzhou. Land Use Policy 2013, 31, 358-370. [CrossRef]

5. Ajibade, I.; McBean, G.; Bezner-Kerr, R. Urban flooding in Lagos, Nigeria: Patterns of vulnerability and resilience among women. Glob. Environ. Chang. Hum. Policy Dimens. 2013, 23, 1714-1725. [CrossRef]

6. Okada, T.; Haynes, K.; Bird, D.; van den Honert, R.; King, D. Recovery and resettlement following the 2011 flash flooding in the Lockyer Valley. Int. J. Disaster Risk Reduct. 2014, 8, 20-31. [CrossRef]

7. Tingsanchali, T. Urban flood disaster management. Procedia Eng. 2012, 32, 25-37. [CrossRef]

8. Wood, H. The Use of Earth Observing Satellites for Hazard Support: Assessments and Scenarios. Final Report of the CEOS Disaster Management Support Group. Available online: http://disaster.ceos.org/legal.cfm (accessed on 13 December 2015).

9. Pradhan, B. Flood susceptible mapping and risk area delineation using logistic regression, GIS and remote sensing. J. Spat. Hydrol. 2010, 9, 1-18.

10. De Risi, R.; Jalayer, F.; de Paola, F. Meso-scale hazard zoning of potentially flood prone areas. J. Hydrol. 2015, 527, 316-325. [CrossRef]

11. Sangati, M. Flash flood analysis and modelling in mountain regions. Ph.D. Theses, University of Padova, Padova, Italy, 2009.

12. Youssef, A.M.; Pradhan, B.; Hassan, A.M. Flash flood risk estimation along the St. Katherine road, southern Sinai, Egypt using GIS based morphometry and satellite imagery. Environ. Earth Sci. 2011, 62, 611-623. [CrossRef]

13. Einfalt, T.; Hatzfeld, F.; Wagner, A.; Seltmann, J.; Castro, D.; Frerichs, S. URBAS: forecasting and management of flash floods in urban areas. Urban Water J. 2009, 6, 369-374. [CrossRef]

14. Kelsch, M. Flood safety: What have historic flash floods taught us? In Proceedings of the AMS Seventh International Conference on School and Popular Meteorological and Oceanographic Education, Boulder, CO, USA, 2-7 July 2006.

15. Xia, J.Q.; Falconer, R.A.; Lin, B.L.; Tan, G.M. Modelling flash flood risk in urban areas. Proc. Inst. Civ. Eng. Water Manag. 2011, 164, 267-282. [CrossRef] 
16. Müller, A. Areas at Risk-Concept and Methods for Urban Flood Risk Assessment. A Case Study of Santiago de Chile. Megacities and Global Change; Kraas, F., Heintzenberg, J., Herrle, P., Kreibich, V., Eds.; Franz Steiner Verlag: Stuttgart, Germany, 2012.

17. Parry, M.L. Assessing the Costs of Adaptation to Climate Change: A Review of the UNFCCC and Other Recent Estimates; International Institute for Environment and Development and Grantham Institute for Climate Change: London, UK, 2009.

18. Dodman, D.; Bicknell, J.; Satterthwaite, D. Adapting Cities to Climate Change: Understanding and Addressing the Development Challenges; Earthscan Publications: London, UK, 2012.

19. Jha, A.K.; Bloch, R.; Lamond, J. Cities and Flooding: A Guide to Integrated Urban Flood Risk Management for the 21st Century; World Bank Publications: Washinton, DC, USA, 2012.

20. Kaburi, A.N.; Odera, P.A. GIS and Remote Sensing Support in Watershed Conservation and Management: Case Study of the Upper Gucha Watershed-Kenya. J. Environ. Sci. Toxic. Food Techn. (IOSR-JESTFT) 2014, 8, 35-43.

21. Srivastava, O.S.; Denis, D.; Srivastava, S.K.; Kumar, M.; Kumar, N. Morphometric analysis of a Semi Urban Watershed, trans Yamuna, draining at Allahabad using Cartosat (DEM) data and GIS. Int. J. Eng. Sci. 2014, 3, 71-79.

22. Amir, M.; Khan, M.; Rasul, M.; Sharma, R.; Akram, F. Watershed delineation and cross-section extraction from DEM for flood modelling. In Proceedings of the 19th Australasian Fluid Mechanics Conference, Melbourne, Australia, 8-11 December 2014; pp. 8-11.

23. Máčka, Z. Determination of texture of topography from large scale contour maps. Geografski vestnik 2001, 73, 53-62.

24. Maidment, D.R. Arc Hydro: GIS for Water Resources; ESRI Press: Redlands, CA, USA, 2002; Volume 1, p. 140.

25. Ozdemir, H.; Bird, D. Evaluation of morphometric parameters of drainage networks derived from topographic maps and DEM in point of floods. Environ. Geol. 2009, 56, 1405-1415. [CrossRef]

26. Dawn, T. Analyzing Wildlife Habitat with Google Earth. Green Teach. 2009, 87, 9-15.

27. Clark, M.L.; Aide, T.M. Virtual Interpretation of Earth Web-Interface Tool (VIEW-IT) for Collecting Land-Use/Land-Cover Reference Data. Remote Sens. 2011, 3, 601-620. [CrossRef]

28. Courtney, R.W.; James, M.; Nancy, M.T.; James, G.M. From Local to Global: A Birds-Eye View of Changing Landscapes. Am. Biol. Teach. 2009, 7, 412-417.

29. David, P. Horizontal Positional Accuracy of Google Earth's High-Resolution Imagery Archive. Sensors 2008, 8, 7973-7981.

30. John, R.T.; Sarah, T.L. Mapping public and private spaces of urban agriculture in Chicago through the analysis of high-resolution aerial images in Google Earth. Landsc. Urban Plan. 2012, 108, 57-70.

31. Antoine, C.; Kazuo, N.; Takashi, N. Mapping VHR Water Depth, Seabed and Land Cover Using Google Earth Data. Int. J. Geo-Inf. 2014, 3, 1157-1179.

32. Scheuren, J.-M.; le Polain, O.; Below, R.; Guha-Sapir, D.; Ponserre, S. Annua disaster statistical review. Available online: https:/ /www.unisdr.org/we/inform/publications/2796 (accessed on 10 June 2015).

33. National Weather Service Office. Definitions of Flood and Flash Flood. Available online: http://www. weather.gov/mrx/flood_and_flash (accessed on 5 December 2015).

34. Associated Programme on Flood Management. Guidance on Flash Flood-Recent Experiences from Central and Eastern Europe. Available online: http://www.apfm.info/projects/pilot/europe/Pilot_Guidance_on_ Flash_Flood_Mgmt_Eastern_Europe.pdf (accessed on 10 May 2014).

35. Nassar, W.M.A.W. The Impact of the Natural Disasters on Re-planning of the Disastered Zones. 2011. Available online: http:/ / www.cpas-egypt.com/AR/Walid_Nassar_ar.html (accessed on 26 October 2016).

36. A Preliminary Report on the Torrent Damage in Aswan; Cairo, Egypt, 2010. Available online: http://www.hmlcegy.org/ (accessed on 10 September 2014).

37. General Organization of Physical Planning. Detailed planning for the village of Abu Rish North-Aswan Governorate; General Organization of Physical Planning: Aswan, Egypt, 2010.

38. Zichuan, Y.; Dean, D. DEM Preprocessing for Efficient Watershed Delineation. ESRI. Available online: http://proceedings.esri.com/library/userconf/proc99/proceed/papers/pap676/p676.htm (accessed on 5 June 2014).

39. Hiep, T.D.; Sebastien, L.; Emmanuel, M. Parallel Computing Flow Accumulation in Large Digital Elevation Models. Procedia Comput. Sci. 2011, 4, 2277-2286. 
40. Li, L.; Xu, Z.X. A Preprocessing Program for Hydrologic Model-A Case Study in the Wei River Basin. Procedia Environ. Sci. 2012, 13, 766-777. [CrossRef]

41. Luo, Y.; Su, B.; Yuan, J.; Li, H.; Zhang, Q. GIS Techniques for Watershed Delineation of SWAT Model in Plain Polders. Procedia Environ. Sci. 2011, 10, 2050-2057. [CrossRef]

42. Liz, I. GIS Tutorial for Watershed Delineation. Available online: http://www.ecs.umass.edu/cee/reckhow/ courses/577/577dp1/GIS\%20Tutorial\%20for\%20Watershed\%20Delineation.pdf (accessed on 8 June 2014).

43. Venkatesh, M. Stream Network and Watershed Delineation using Spatial Analyst Hydrology Tools. Available online: http://web.ics.purdue.edu/ vmerwade/education/hydrology.pdf (accessed on 5 June 2014).

(C) 2016 by the authors; licensee MDPI, Basel, Switzerland. This article is an open access article distributed under the terms and conditions of the Creative Commons Attribution (CC-BY) license (http://creativecommons.org/licenses/by/4.0/). 